\title{
Abundance of Large Carnivore and its Prey Species after Removal of Cattle Grazing in Mundanthurai Plateau of Kalakad-Mundanthurai Tiger Reserve, Tamil Nadu, India
}

\author{
Venkatesh A', Sridharan $\mathbf{N}^{1}$, Packiavathi AJ1 and Selvan $\mathbf{M}^{2 *}$ \\ ${ }^{1}$ Kalakad-Mundanthurai Tiger Reserve, Tamil Nadu, India \\ ${ }^{2}$ Salim Ali School of Ecology and Environmental Sciences, Pondicherry University, Puducherry, India
}

\begin{abstract}
Large carnivores are experiencing massive decline in their population and abundance due to loss of habitat and loss of prey species. The present study was carried out in Mundanthurai Pleateu of Kalakad-Mundanthurai Tiger Reserve, Tamil Nadu, India. In Mundanthurai Plateau, Tiger Panthera tigris has been absent in past two decades which is linked with low density of large ungulate prey species such as gaur and sambar. In this study we examined the status of large carnivore and prey species after the removal of cattle grazing in the plateau. The study reveals that the overall density of ungulate prey species was $12.4 \pm 1.5 / \mathrm{Km}^{2}$ and gaur density found to be $3.37 \pm 1.40 / \mathrm{Km}^{2}$. The available prey biomass of $3282.02 \mathrm{~kg}$ can support around 11 tigers $/ 100 \mathrm{Km}^{2}$ and it may be lower due to biomass which is shared by other sympatric carnivores. The present estimated leopard density in the plateau is $24.32 \pm 4.38$ using camera traps spatially explicit capture-recapture method. Overabundance of leopard may be due to the absence of tiger in the plateau and we have confirmed the presence of one male tiger in the plateau so far. The present study may provide baseline information on monitoring tigers and co-predators in the Mundanthurai Plateau of Kalakad Mundanthurai Tiger Reserve.
\end{abstract}

Keywords: Prey species; Biomass; Western Ghats; Mundanthurai plateau

\section{Introduction}

The abundance of larger carnivores is directly related to the large herbivore abundance and its distribution [1,2]. Terrestrial mammalian prey is important to maintain the large carnivore population and insufficient prey will leads to locally extinction of the carnivore species [3]. For example, the decline in tiger population worldwide mainly liked with prey density [4] along with habitat loss and poaching [5]. The Ungulate density is the key determinants for large felids [6] and in majority of the Indian forest large ungulates play a major role in shaping the carnivore communities especially in South, Central and Eastern Indian forests $[7,8]$. Prey preference of large carnivores such as tiger Panthera tigris mainly depending upon the prey size and age [7] and fluctuation in prey abundance may change the rate of prey consumption of mammalian vertebrate predators [9].

The present study was conducted in Mundanthurai Plateau of Kalakad Mundanthurai Tiger Reserve, Tamil Nadu. Past studies imply that absence of tiger in the Mundanthurai plateau of Kalakad Mundanthurai Tiger Reserve, Tamil Nadu which is mainly linked with low density of large herbivores [4] like gaur and sambar. After the year of 2000, cattle grazing was banned from the Plateau and the recent surveys revealed the movement of larger prey in plateau and its increased abundance. In the present study, we examined how, ban on cattle grazing is influenced the prey species recovery in Mundanturai plateau. The major question here is to answers, are there enough prey biomass in Mundanthurai Pleateu to support large carnivores? What is population status of sympatric large carnivores such as Tiger Panthera tigris, leopard Panthera pardus, dhole Cuon alpinus and sloth bear Melursus ursinus in the Mundanturai plateau.

\section{Study area}

The study was carried out intensively in Mundanthurai plateau $\left(8^{\circ} 23^{\prime}-9^{\circ} 0^{\prime} \mathrm{N}\right.$ and $\left.77^{\circ} 8^{\prime}-77^{\circ} 33^{\prime} \mathrm{E}\right)$ of Kalakad Mundanthurai Tiger Reserve, Tamil Nadu which is situated in the Ashambu Hills of the southern Western Ghats (southern India), with core area of $895 \mathrm{~km}^{2}$.
This region is topographically diverse and supports vegetation such as dry thorn forests, deciduous forests, grasslands and wet evergreen rain forests. It is a priority area for conservation of its rich floral and faunal diversity, both in terms of species richness and endemism. The forests of the Reserve are important catchment for as many as fourteen rivers and streams originating from the reserve, hence is also called a River Sanctuary [10]. KMTR also supports viable populations of endangered mammals such as the Tiger (Panthera tigiris), the Asian elephant (Elephas maximus) and the endemic Lion tailed Macaque (Macaca silenus) [11]. It is the only plateau in KMTR with varying altitudinal range from $180 \mathrm{~m}$ to $220 \mathrm{~m}$. Annual rainfall averages about $1189 \mathrm{~mm}$. Dry deciduous forests, riparian fringe forest, plantations and thorny scrub forests collectively comprise the most prevalent habitat types in the plateau (Figure 1).

\section{Methodology}

\section{Prey estimation}

Transect method $[12,13]$ was used to estimate densities of prey species in the study area. This method has been widely applied to estimate densities of prey species [6,7,14-17]. Totally five line transects of varying length from 1.5 to $2.0 \mathrm{~km}$ were laid in the study area covering all major vegetation types to ensure uniform distribution without leaving any large gaps between transects. The total transect length of 50

*Corresponding author: Muthamizh Selvan, DST INSPIRE Faculty, Salim Ali School of Ecology and Environmental Sciences, Pondicherry University, Puducherry, India, Tel: +918904110526; E-mail: tamildove@gmail.com

Received December 05, 2016; Accepted January 17, 2017; Published January 25, 2017

Citation: Venkatesh A, Sridharan N, Packiavathi AJ, Selvan M (2017) Abundance of Large Carnivore and its Prey Species after Removal of Cattle Grazing in Mundanthurai Plateau of Kalakad-Mundanthurai Tiger Reserve, Tamil Nadu, India J Biodivers Endanger Species 5: 178. doi: 10.4172/2332-2543.1000178

Copyright: (c) 2017 Venkatesh A, et al. This is an open-access article distributed under the terms of the Creative Commons Attribution License, which permits unrestricted use, distribution, and reproduction in any medium, provided the original author and source are credited. 


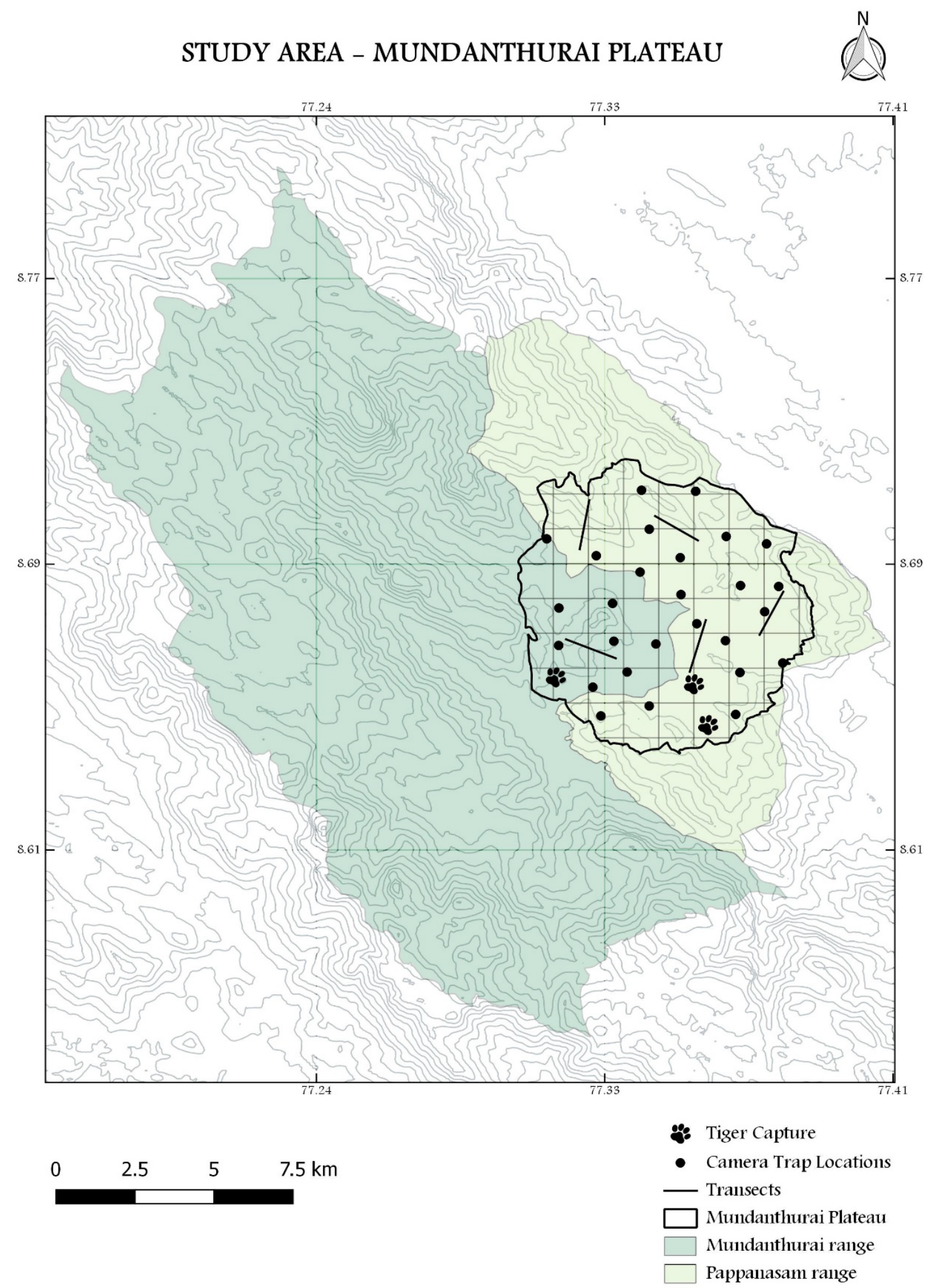

Figure 1: Study area map showing the Camera trap and line transects locations in the Plateau. 
Citation: Venkatesh A, Sridharan N, Packiavathi AJ, Selvan M (2017) Abundance of Large Carnivore and its Prey Species after Removal of Cattle Grazing in Mundanthurai Plateau of Kalakad-Mundanthurai Tiger Reserve, Tamil Nadu, India. J Biodivers Endanger Species 5: 178. doi: $10.4172 / 2332-2543.1000178$

Page 3 of 5

$\mathrm{km}$ was monitored five times during the beginning of the day (06:3009:00 hrs). For each sighting along transect, the following parameters were recorded:

1. Sighting angle using a hand held compass

2. Sighting distance using a range finder (Bushnell)

3. Group size

4. Sex and age class of individuals (whenever possible).

For each prey species sighting on a transect, the following were recorded:

\section{Total number of individuals}

2. Animal bearing

3. Angular sighting distance.

Prey density was calculated using the program Distance 6.0 [18] Density was calculated after $1 \%$ truncation of the farthest sighting data from line transect. Different detection functions were fitted to the observed data and the best model was selected on the basis of the lowest Akaike Information Criterion (AIC) values [12,13]. To achieve reliable estimates and model detection functions, a minimum of 40 observations are required. Chital, sambar, gaur, wild pig, and langur are substantially active in the morning, therefore their density and available biomass were estimated.

\section{Camera trap survey}

We intensively monitored prey and predator population using camera traps in KMTR. The camera traps were placed in entire Mundanthurai plateau of KMTR and the plateau was gridded by $2 \mathrm{~km} \times$ $2 \mathrm{~km}(\mathrm{n}=30)$ and each grid was placed with pair of Cuddy back camera. The camera was placed in metal cage so as to avoid the damaged by Asiatic elephant or being theft. We maintained inter camera distance of $1.5 \mathrm{~km}$ to $2 \mathrm{~km}$ and the cameras were active for $24 \mathrm{hrs}$. Capture-MarkRecapture method was used for individually identifiable species such as Tiger and leopard and Photographic encounter rate was used for individually non identifiable species like dhole and sloth bear. Lowest AIC value was considered best for parameter estimates in program MARK [19]. To estimate the population density of leopard program DENSITY 4.4 [20] was used. The leopard density $( \pm$ SE)/100 km² using 1/2 MMDM and MMDM and Maximum Likelihood methods were estimated.

\section{Results}

\section{Prey density and prey biomass}

A total of $50 \mathrm{Km}$ transects were surveyed and several prey species were detected. Density estimates for five potential prey species were computed (Gaur, Chital, Sambar, Nilgiri langur, Wild pig, and Jungle fowl). The overall density of ungulate prey species was $12.4 \pm 1.5 / \mathrm{Km}^{2}$ and the density of sambar $\left(4.59 \pm 1.25 / \mathrm{Km}^{2}\right)$ was highest followed by gaur $\left(3.37 \pm 1.40 / \mathrm{Km}^{2}\right)$ and wild boar $\left(3.11 \pm 1.67 / \mathrm{Km}^{2}\right)$. We surveyed entire Mundanthurai plateau and were able to distinguish nine herds of chital with $70-80$ individuals. The herd size varied from 3-12 individuals and density of chital was $1.33 \pm 0.43 / \mathrm{Km}^{2}$. The density of jungle fowl was $33.89 \pm 15.04 / \mathrm{Km}^{2}$. The total available prey biomass in the study area was estimated to be $3282.02 \mathrm{~kg}$. The estimated mean biomass/sq.km of different prey species in the study area was chital $46.87 \mathrm{~kg}$, gaur $1011 \mathrm{~kg}$, sambar $688.5 \mathrm{~kg}$, nilgiri langur $64.62 \mathrm{~kg}$ and wild pig $124.4 \mathrm{~kg}$.

\section{Large carnivores abundance}

The total sampling effort of 1,800 trap nights for 60 days yielded 9 photographs of tiger (five right flanked and four left flanked), 148 photographs of leopard (74 right flanked and 74 left flanked), dhole 481 and sloth bear 89 photographs. One individual tiger was identified from both right and left flank photos. Twenty-three individuals of leopard were identified from the left flank photos and twenty individual leopards from the right flank photos.

A total of $77.6 \mathrm{Km}$ was surveyed for large carnivore signs during the study period. The study recorded a highest sign encounter rate for sloth bear $\left(0.70 / \mathrm{km}^{-1}\right)$, followed by leopard $\left(0.67 / \mathrm{km}^{-1}\right)$ and dhole $\left(0.41 / \mathrm{km}^{-1}\right)$ within the Mundanthurai plateau. Tiger signs were also recorded during the survey. Sign survey results showed the presence of all three large carnivores (Sloth bear, leopard and dhole) across all vegetation types of the plateau. The highest encounter rate of carnivore was recorded in dry deciduous forest $\left(0.79 / \mathrm{km}^{-1}\right)$ followed by scrub jungle $\left(0.63 / \mathrm{km}^{-1}\right)$, riparian forest $\left(0.32 / \mathrm{km}^{-1}\right)$ and plantations $(0.06 /$ $\mathrm{km}^{-1}$ ) (Table 1).

The leopard density ranged from 16.62 to 27.36 individuals 100 $\mathrm{km}^{2}$ using different statistical methods. Statistical tests for population closure supported for leopard is $\mathrm{P}=0.97$ (Table 2).

Mean photographic encounter rate (no of photo captures/100 trap nights) was calculated for tiger, leopard, dhole and their prey species. Among the carnivores dhole $(1.14 \pm 0.24)$ has highest photographic encounter rate followed by leopard $(0.44 \pm 0.08)$ and tiger $(0.03 \pm 0.02)$

\begin{tabular}{|c|c|c|c|c|c|c|c|}
\hline Species & Total Effort (Km) & Model & No of group & $E S W \pm S E$ & $\mathbf{P}$ & $\mathrm{Dg} \pm \mathrm{SE}$ & $\mathrm{D} \pm \mathrm{SE}$ \\
\hline Gaur & 50 & Uniform/Simple Polynomial & 8 & $47.93 \pm 10.24$ & 0.98 & $1.66 \pm 0.43$ & $3.37 \pm 1.40$ \\
\hline Sambar & 50 & Uniform/Simple Polynomial & 10 & $32.11 \pm 3.84$ & 0.64 & $3.11 \pm 0.78$ & $4.59 \pm 1.25$ \\
\hline Wild boar & 50 & Uniform/Simple Polynomial & 6 & $39.04 \pm 12.94$ & 0.84 & $1.28 \pm 0.71$ & $3.11 \pm 1.67$ \\
\hline Nilgiri Langur & 50 & Uniform/Simple Polynomial & 8 & $62.24 \pm 6.48$ & 0.77 & $1.28 \pm 0.67$ & $7.18 \pm 3.57$ \\
\hline Jungle fowl & 50 & Half normal/Cosine & 39 & $12.44 \pm 1.59$ & 0.5 & - & $33.89 \pm 15.04$ \\
\hline
\end{tabular}

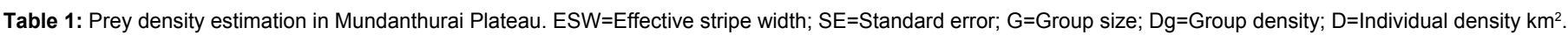

\begin{tabular}{|c|c|c|c|c|c|c|c|}
\hline Species & No of individual captured & Best Model & Methods & P hat & $\mathrm{N} \pm \mathrm{SE}$ & ETA & $\mathrm{D} \pm \mathrm{SE}$ \\
\hline \multirow{3}{*}{ Leopard } & \multirow{2}{*}{23} & \multirow{2}{*}{ Mo } & 1/2 MMDM & 0.05 & $24.0 \pm 1.3$ & 87.72 & $16.62 \pm 3.42$ \\
\hline & & & MMDM & & & 144.435 & $27.36 \pm 3.37$ \\
\hline & & & Max likelihood & & & & $24.32 \pm 4.38$ \\
\hline
\end{tabular}

Table 2: Population estimation of leopard in the intensive camera survey area. Mo=Null model; $1 / 2 \mathrm{MMDM}=$ Half mean maximum distance moved; $P$ hat=Capture probability $\mathrm{N}=$ Population size; $\mathrm{SE}=$ Standard error; $\mathrm{MMDM}=$ mean maximum distance moved; $\mathrm{ETA}=$ Effective trapping area; $\mathrm{D}=\mathrm{Number}$ of individuals $/ 100 \mathrm{~km}{ }^{2}$. 
Citation: Venkatesh A, Sridharan N, Packiavathi AJ, Selvan M (2017) Abundance of Large Carnivore and its Prey Species after Removal of Cattle Grazing in Mundanthurai Plateau of Kalakad-Mundanthurai Tiger Reserve, Tamil Nadu, India. J Biodivers Endanger Species 5: 178. doi: $10.4172 / 2332-2543.1000178$

Page 4 of 5

Among the prey species sambar $(1.94 \pm 0.78)$ has highest photographic encounter rate followed by gaur $(1.59 \pm 0.49)$, wild pig $(1.45 \pm 0.31)$ and peafowl $(0.95 \pm 0.27)$.

\section{Discussion}

The present study was conducted to estimate the abundance and densities of large carnivore and its prey species in Mundanthurai Pleateu after the ban on cattle grazing. Since last two decades' tiger was absence in the pleateu though its connected with tiger presence area. Predator densities have been attributed to habitat availability [21], prey availability [22] and protection level [23]. The high abundance of different prey species in the present study may be due to the availability of space and food plants. Ban on cattle grazing would have been opened up variety of habitat availability to the native ungulate species, this could probably have led to the high abundance of herbivore species. Sambar has been observed to be the most abundant prey species in the study area followed by gaur. The density of gaur is high in Mundanthurai plateau and the movement of gaur was recorded up to lower dam of Papanasam range. Totally seven different herds of gaur were found in the plateau and the number of individuals vary from 1 to 17 . The Mundanthurai forest area has become so thick, wooded and presence of Strobilanthes $s p$ also may support the guar presence. Strobilanthes $s p$ is observed to be preferred food plants of gaur and this indicates the qualitative improvement of habitat. However, the extent of gaur presence insists the establishment of tiger in Mundanthurai plateau in near future.

The chital population seems to be decreasing due to the declining open grasslands which have been replaced by thick vegetation or by fire resistant grass species like lemon grass and dense thorny vegetation in many parts of the dry deciduous habitat. It has been observed that chital do not prefer lemon grass dominated grasslands. The finding of this study suggests that the density of prey species is lower than other deciduous forests in India, however the low density of large prey may not adversely affect the leopard population. Leopards are opportunistic and are very flexible in their diet and can thus survive in a region where ungulate densities are low. Their ability to feed on both small and large prey, to climb trees and scavenge [24] helps to survive in a highly disturbed habitat where prey is scarce. Leopard density determined in our study is fairly high in comparison to other reported estimates in the country [25-27] and it can survive with smaller prey such as rodents and langurs [28]. Though the study could not estimate the actual density of Asiatic wild dog, there could be 5 packs (Avg pack size $6 \leq 3$ ) operating in the Plateau area. The overall estimated prey biomass is $3282.02 \mathrm{~kg} / \mathrm{sq} . \mathrm{km}$ which easily can support around 11 tigers $/ 100 \mathrm{~km}^{2}$, since the tiger shares the biomass with co-predators it can be low in abundance. Though, present study has confirmed the movements of tiger in the plateau, till it is not assured whether the tiger has established its territory since the recapture rate is low. However, there are higher chances of territory establishments of dispersed tigers in the Mundanthurai Plateau. Given a chance of tiger establishing its territory, further study would be requiring to understand the intraguild competition between these two predators. If tiger forces leopard to periphery [29], there might be a chance for human leopard conflict in the fringe villages.

Kalakad Mundanthurai Tiger Reserve being the most important conservation unit linking Western Ghats requires habitat protection along with regular monitoring of large carnivores and their prey population with the incorporation of robust scientific methods. This study has provided important baseline information for long-term monitoring of tigers and copredators in Kalakad Mundanthurai Tiger reserve.

\section{Acknowledgements}

We thank the Principal Chief Conservator of Forests and Chief Wildlife warden for continuous encouragement and technical support. We also thank the Additional chief conservator of Forests. Project Tiger for the generous support. Corresponding author would like to thank DST Inspire faculty program for providing opportunity to work in KMTR. We are also grateful to our colleagues, Mr. C. Murugan Chellappa Mrs. R. Diana and field assistants lyyanar and Karthik for their immense support in data collection.

\section{References}

1. Ramesh T, Kalle R, Sankar K, Qureshi Q (2012) Spatio-temporal partitioning among large carnivores in relation to major prey species in Western Ghats. J Zoo 4: 269-275.

2. Selvan KM, Lyngdoh S, Gopi GV, Habib B, Hussain SA (2014) Population density and abundance of sympatric large carnivores in the lowland tropical evergreen forest of Indian Eastern Himalayas. Acta Ecologica Sinica 79: 254258.

3. Wolf C, Ripple WJ (2016) Prey depletion as a threat to the world's large carnivores. R Soc open sci 3: p 160252

4. Ramakrishnan U, Coss RG, Pelkey NW (1999) Tiger decline caused by the reduction of large ungulate prey: evidence from a study of leopard diets in southern India. Biological Conservation 89: 113-120.

5. Nowell K, Jackson P (1996) Wild Cats, Status Survey and Conservation Action Plan. IUCN Publication Services Unit Cambridge.

6. Karanth KU, Nichols JD, Kumar NS, Link WA, Hines JE (2004) Tigers and their prey: predicting carnivore densities from prey abundance. Proc Natl Acad Sci USA 101: 4854-4858.

7. Karanth KU, Sunquist ME (1995) Prey selection by tiger, leopard and dhole in tropical forests. J Anim Ecol 64: 439-450.

8. Andheria AP, Karanth KU, Kumar NS (2007) Diet and prey profiles of three sympatric large carnivores in Bandipur Tiger Reserve, India. J of Zoo 273: 169-175.

9. Randa LA, Cooper DM, Meserve PI, Yunger JA (2009) Prey switching of sympatric canids in response to variable prey abundance. J Mammal 90: 594-603.

10. Melkani VK (2001) Involving local people in biodiversity conservation in Kalakad Mundanthurai Tiger Reserve-An Overview. Curr Sci 80: 437-441.

11. Johnsingh AJT (2001) The Kalakad-Mundanthurai Tiger Reserve: A global heritage of biological diversity. Curr Sci 80: 378-388

12. Burnham KP, Anderson DR, Laake JL (1980) Estimation of density from line transects sampling of biological populations. Wild Mono 72: 1-202.

13. Buckland ST, Anderson DR, Burnham KP, Laake JL, Borchers DL, et al (2004) Introduction to distance sampling: estimating abundance of biological populations. Oxford University Press, Oxford.

14. Karanth KU, Sunquist ME (1992) Population structure, density and biomass of Large herbivores in the tropical forests of Nagarahole, India. J Tropical Ecol 8: 21-35.

15. Biswas S, Sankar K (2002) Prey abundance and food habit of tigers (Panthera tigris tigris) in Pench National Park, Madhya Pradesh, India. J Zoo 411-422.

16. Bagchi S, Goyal SP, Sankar K (2003) Prey abundance and prey selection by tigers (Panthera tigris) in a semi arid, dry deciduous forest in western India. J Zoo 285-290.

17. Jathanna D, Johnsingh AJT, Karanth UK (2003) Estimation of large herbivore densities in the tropical forests of southern India using distance sampling. J Zoo 285-290.

18. Thomas LJ, Laake L, Rexstad E, Strindberg S, Marques FFC, et al. (2009) Distance 6.0 Research Unit for Wildlife Population Assessment. University of St Andrews, UK.

19. Burnham B, Kenneth P, David RA (1998) Model Selection and Inference: A Practical Information-Theoretical Approach. New York: Springer-Verlag.

20. Borchers DL, Efford MG (2008) Spatially explicit maximum likelihood methods for capture-recapture studies. Biomet 64: 377-385

21. Wikramanayake ED, Dinerstein E, Robinson JG, Karanth U, Rabinowitz A, et al. (1998) An ecology-based method for defining priorities for large mammal conservation: The tiger as case study. Conserv Biol 12: 865-887. 
Citation: Venkatesh A, Sridharan N, Packiavathi AJ, Selvan M (2017) Abundance of Large Carnivore and its Prey Species after Removal of Cattle Grazing in Mundanthurai Plateau of Kalakad-Mundanthurai Tiger Reserve, Tamil Nadu, India. J Biodivers Endanger Species 5: 178. doi: 10.4172/2332-2543.1000178

Page 5 of 5

22. Karanth KU, Stith BM (1999) Prey depletion as a critical determinant of tiger population viability. In: Riding the tiger: tiger conservation in human-dominated landscapes, pp: 100-113.

23. Kenney JJ, Smith LD, Starfield AM, McDougal CW (1995) The Long Term Effect of Tiger Poaching on Population Viability. Conserv Biol 9: 1127-1133.

24. Johnsingh AJT (1983) Large mammalian prey-predator in Bandipur. JBNHS 80: $1-57$.

25. Sankar K, Qureshi Q, Mondal K, Worah D, Srivastava T, et al. (2008) Ecological studies in Sariska Tiger Reserve, Rajasthan. Wildlife Institute of India, Dehradun.
26. Edgaonkar A, Chellam R, Qureshi Q (2007) Ecology of the leopard (Panthera pardus fusca) in Satpura National Park and Bori Wildlife Sanctuary. Wildlife Institute of India, Dehradun.

27. Harihar A, Bivash P, Goyal SP (2009) Responses of tiger (Panthera tigris) and their prey to removal of anthropogenic influences in Rajaji National Park, India. Eur J Wildl Res 55: 97-105.

28. Selvan KM, Gopi GV, Lyngdoh S, Habib B, Hussain SA (2013) Prey selection by sympatric carnivores in a tropical forest of Arunachal Pradesh. Mamm Biol 78: 296-393.

29. Harihar A, Pandav B, Goyal SP (2011) Responses of leopard Panthera pardus to the recovery of a tiger Panthera tigris population. J of Appl Eco 48: 806-814. 